Hydrology and Earth System Sciences, 9, 263-278, 2005

www.copernicus.org/EGU/hess/hess/9/263/

SRef-ID: 1607-7938/hess/2005-9-263

European Geosciences Union

(1)

\title{
Hydroclimatology of the Nile: results from a regional climate model
}

\author{
Y. A. Mohamed ${ }^{1}$, B. J. J. M. van den Hurk ${ }^{2}$, H. H. G. Savenije ${ }^{1,3}$, and W. G. M. Bastiaanssen ${ }^{4}$ \\ ${ }^{1}$ UNESCO-IHE, P.O. Box 3015, 2601 DA Delft, The Netherlands \\ ${ }^{2}$ KNMI, P.O. Box 201, 3730 AE De Bilt, The Netherlands \\ ${ }^{3}$ Delft University of Technology, Stevinweg 1, 2628 CN Delft, The Netherlands \\ ${ }^{4}$ ITC (currently with WaterWatch), Generaal Foulkesweg 28, 6703 BS Wageningen, The Netherlands
}

Received: 6 January 2005 - Published in Hydrology and Earth System Sciences Discussions: 10 February 2005

Revised: 10 August 2005 - Accepted: 6 September 2005 - Published: 26 September 2005

\begin{abstract}
This paper presents the result of the regional coupled climatic and hydrologic model of the Nile Basin. For the first time the interaction between the climatic processes and the hydrological processes on the land surface have been fully coupled. The hydrological model is driven by the rainfall and the energy available for evaporation generated in the climate model, and the runoff generated in the catchment is again routed over the wetlands of the Nile to supply moisture for atmospheric feedback. The results obtained are quite satisfactory given the extremely low runoff coefficients in the catchment.
\end{abstract}

The paper presents the validation results over the subbasins: Blue Nile, White Nile, Atbara river, the Sudd swamps, and the Main Nile for the period 1995 to 2000. Observational datasets were used to evaluate the model results including radiation, precipitation, runoff and evaporation data. The evaporation data were derived from satellite images over a major part of the Upper Nile. Limitations in both the observational data and the model are discussed. It is concluded that the model provides a sound representation of the regional water cycle over the Nile. The sources of atmospheric moisture to the basin, and location of convergence/divergence fields could be accurately illustrated. The model is used to describe the regional water cycle in the Nile basin in terms of atmospheric fluxes, land surface fluxes and land surface-climate feedbacks. The monthly moisture recycling ratio (i.e. locally generated/total precipitation) over the Nile varies between 8 and 14\%, with an annual mean of $11 \%$, which implies that $89 \%$ of the Nile water resources originates from outside the basin physical boundaries. The monthly precipitation efficiency varies between 12 and 53\%, and the annual mean is $28 \%$. The mean annual result of the Nile regional water cycle is compared to that of the Amazon and the Mississippi basins.

Correspondence to: Y. A. Mohamed

(yasir1@unesco-ihe.org)

\section{Introduction}

It is increasingly recognized that appropriate water resources planning and management at a river basin level is viable only by considering the complete water cycle in the basin, i.e. including both the land surface (hydrological) and the atmospheric processes. In many river basins, steady climatic conditions are no longer considered a valid assumption for sustainable water resources management. Therefore, despite its significant computational effort water resources studies at river basin level are increasingly linked to regional climate studies. Examples are studies on impact of climate change/variability on water resources or the studies of land use change and their impacts on regional climate and water resources (see a review in Watson et al., 2001). Similarly, it is appreciated that adequate representation of the land surface in climate models is crucial for accurate modeling results (e.g. Kite, 1998; Koster et al., 2002).

The Nile Basin experiences rising demands for its (limited) water resources. As a result, there is increasing pressure to augment river discharge by reducing the non-beneficial evaporation losses from the Upper Nile swamps. In the Sudd, the Nile evaporates more than half of its local flow, i.e. around $29 \mathrm{Gm}^{3} / \mathrm{yr}$ out of the long-term mean of $49 \mathrm{Gm}^{3} / \mathrm{yr}$ (mean of 1961-1983). The proposed approach for water saving is to build river short-cut channels to prevent spillage into the swamps and divert the flows downstream into the main channel (e.g. the uncompleted Jonglei canal). Although these plans for the Nile Swamps were initiated about 100 years ago, and associated with intensive environmental impact assessment studies (see a review in Howell et al., 1988), no genuine attempts have been made to study the impact on the regional climate. A coupled regional climate model (RCM) would enhance the understanding of the complete water cycle and the imbedded feedbacks, allowing a more integrated approach of water resources planning in response to the critical water shortage in the Nile. In the absence of a good

(C) 2005 Author(s). This work is licensed under a Creative Commons License. 

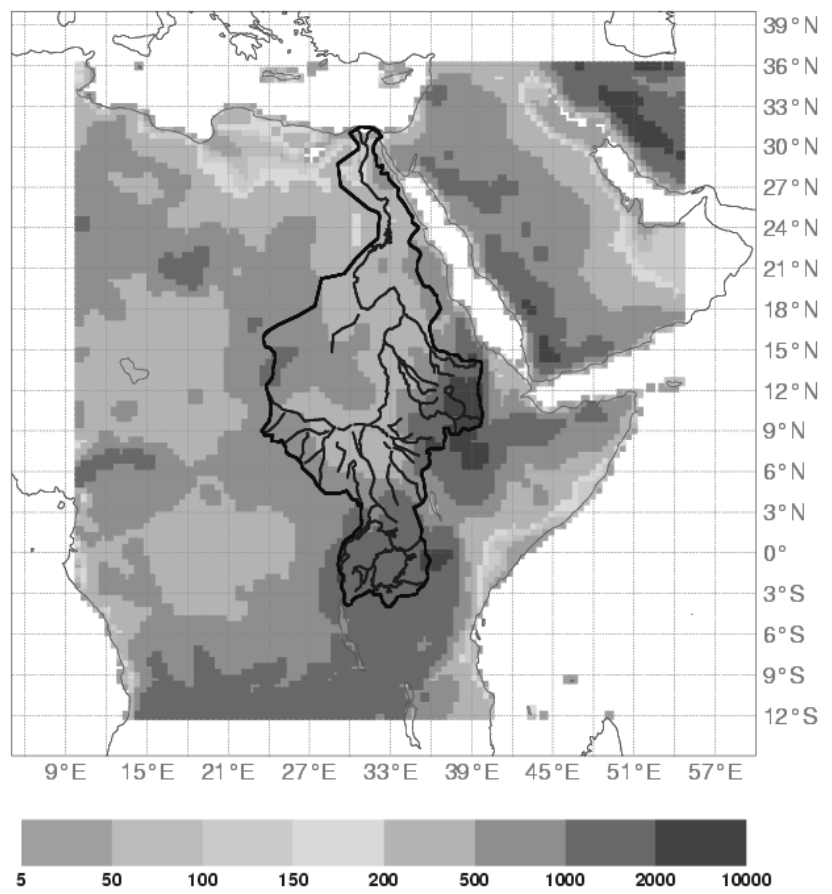

Fig. 1. Location and topography of the Nile Basin (m+MSL).

understanding of the Nile water cycle, different and sometimes contradictory conclusions were drawn on the impact of the Sudd wetlands on the climate regime of the Nile (Eagleson, 1986; Eltahir, 1989; Sutcliffe and Parks, 1999).

Worldwide, RCM's are used for a variety of applications related to the hydrology and water resources of river basins (see e.g. a review of Giorgi and Mearns, 1999). Bonan (1995) and Sun et al. (1999a) used RCM's to study the influence of the Nile source water (Equatorial lakes) on the regional climate. They demonstrated a strong atmosphere-lake interaction that significantly modulates the regional climate of East Africa. Sun et al. (1999b) also showed that there is a strong positive correlation between the Upper Nile precipitation (over lake Victoria) and the warm El Niño-Southern Oscillations ENSO. This is also confirmed by Farmer (1988), Nicholson (1996) and others. Results from Global Climate Models (GCM) were used to study the impact of climate change/variability on the Nile water resources, e.g. Conway and Hulme (1996). The IPCC Third Assessment Report, Working Group II (Watson et al., 2001) gives a review of the possible impacts of climate change on the Nile water resources. The report shows the difficulty in predicting the Nile response to global warming because of the fact that different simulations give conflicting results. Unlike the Amazon and the Mississippi basins, no RCM study has been made to investigate the impact of land use changes on the Nile climate.

In the present study, the Regional Atmospheric Climate MOdel RACMO (Lenderink et al., 2003) is run over the Nile for the period 1995 to 2000. The objective is to obtain a better understanding of the water cycle over the Nile and the em- bedded feedbacks between land and atmosphere. The model is forced by the ERA-40 (ECMWF Re-analysis 1957-2001) boundary condition, and adjusted to simulate the routing of the Nile flow over the Sudd swamps. Model evaluation is based on observational datasets of various sources: radiation, precipitation, evaporation and runoff.

The validated model has been used to compute the moisture recycling over the basin. The amount of precipitation recycling in an area is defined as the ratio of the locally generated precipitation to the total precipitation within that area (Budyko, 1974; Brubaker et al., 1993; Savenije, 1995). Earlier results made by a GCM show a considerable precipitation recycling over East Africa including the Nile Basin. By using particle tracers in GCM simulations on an $8 \times 10^{\circ}$ model grid, Koster et al. (1986) claimed a significant contribution of the evaporated water from the Sudd to the regional rainfall. Using the same methodology, but with a finer GCM, Bosilovich et al. (2002) showed that a substantial percentage of precipitation over the Nile basin is originated from land evaporation (could be outside the basin). The outcome of these results is limited due to the coarse model resolution that misses the details of the Upper Nile swamps. In the present study, moisture recycling has been determined from a much finer resolution RCM (50 km horizontal resolution).

The objective of this paper is to present and discuss the validation results of the Nile climate model with particular emphasis on the hydrology of the upstream wetlands, and moisture recycling ratios. Although the moisture recycling ratio may give further insight into the characteristics of a regional water cycle, it has no prognostic value. E.g. it may not be possible to predict accurately changes of regional precipitation due to alteration of the recycling ratio. The recycling ratio is based on the atmospheric water balance, without consideration of the other thermodynamic processes. The impact of land use change on climate can only be assessed with RCM simulations for different scenarios of land use. In a second paper we explain the application of the same model to a land use change scenario over the Nile (drained wetlands).

A brief description of the basic features of the Nile hydroclimatology is first given as a background to evaluate the modeling results. The basic features of the regional climate model are outlined in Sect. 3, together with the required adjustments to simulate the wetland hydrology. The observational datasets are discussed in Sect. 4, followed by a comparison of model results vs. observations in Sect. 5, as well as the results on moisture recycling. Finally a conclusion on the discussion of the modeling results is given in Sect. 6.

\section{Basic hydroclimatology of the Nile}

The Nile basin covers an area of over 3 million $\mathrm{km}^{2}$, and a length of about $6700 \mathrm{~km}$, longest in the world. The basin extends from $4^{\circ} \mathrm{S}$ to $32^{\circ} \mathrm{N}$, stretching over different geographical, climatological and topographical regions (Fig. 1). 


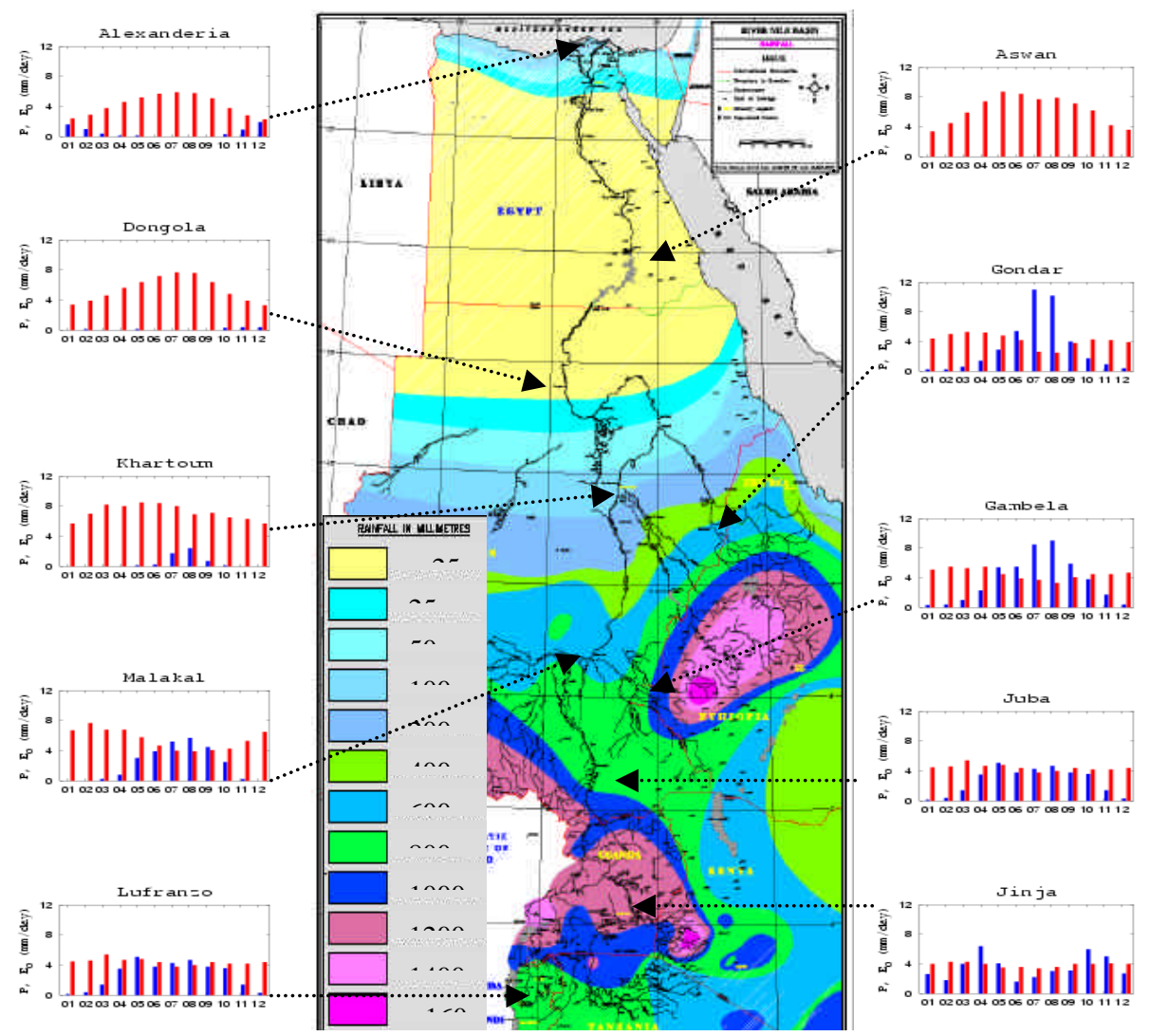

Fig. 2. Mean annual rainfall in $\mathrm{mm} / \mathrm{yr}$ (source: Nile Basin Atlas, TECCONILE). Mean monthly precipitation $P$ (blue), and potential evaporation $E_{0}$ (red) in mm/day at key stations (source: Smith, 1993).

Besides the two plateaus in Ethiopia and around the equatorial lakes (Victoria, Albert, Kayoga, Edward), the Nile Basin can be considered as a large flat plain, in particular the White Nile sub-basin.

\subsection{Climate}

The climate characteristics and vegetation cover in the basin are closely correlated with the amount of precipitation (Fig. 2). Precipitation is to a large extent governed by the movement of the Inter-Tropical Convergence Zone (ITCZ) and the land topography. In general, precipitation increases southward, and with altitude (note the curvature of the rain isoheights parallel to the Ethiopian Plateau). Precipitation is virtually zero in the Sahara desert, and increases southward to about 1200-1600 mm/yr on the Ethiopian and Equatorial lakes Plateaus. Two oceanic sources supply the atmospheric moisture over the Nile basin; the Atlantic and the Indian Oceans.

The seasonal pattern of rainfall in the basin follows the movement of the ITCZ. The ITCZ is formed where the dry northeast winds meet the wet southwest winds. As these winds converge, moist air is forced upward, causing water vapor to condense. The ITCZ moves seasonally, drawn toward the area of most intense solar heating or warmest sur- face temperatures. Normally by late August/early September it reaches its most northerly position up to $20^{\circ} \mathrm{N}$. Moist air from both the equatorial Atlantic and the Indian Ocean flows inland and encounters topographic barriers over the Ethiopian Plateau that lead to intense precipitation, responsible for the strongly seasonal discharge pattern of the Blue Nile. The retreat of the rainy season in the central part of the basin from October onwards is characterized by a southward shift of the ITCZ (following the migration of the overhead sun), and the disappearance of the tropical easterly jet in the upper troposphere.

The monthly distribution of precipitation over the basin shows a single long wet season over the Ethiopian plateau, and two rainy seasons over the Equatorial Lakes Plateau as given in Fig. 2 for some of the key stations in the basin. Potential evaporation (in this case equivalent to the reference crop evaporation) data $E_{0}$ are also plotted. $E_{0}$ is the evaporation from a hypothetical grass crop $12 \mathrm{~cm}$ high with no moisture constraints, surface resistance of $70 \mathrm{~s} / \mathrm{m}$ and an albedo of 0.23 . The $E_{0}$ shows trends opposite to the precipitation, i.e. increases in northward direction. The climatology of the dry and hot atmosphere near Lake Aswan has a reference crop evaporation being twice the value for Upper Nile stations near Lake Victoria. 
Table 1. Catchment areas and mean annual flows of the sub-basins. * Mean river natural flows for the period $\sim 1910$ to 1995 (source: Sutcliffe and Parks, 1999).

\begin{tabular}{cccccc}
\hline No. & Catchment & Outlet location & Area $\mathrm{Gm}^{2}$ & No. of model grid points & Annual flow $\mathrm{Gm}^{3} / \mathrm{yr}^{*}$ \\
\hline 1. & Nile & Mediterranean & 3310 & 1378 & \\
2. & Nile & Aswan & 3060 & 1274 & 84.1 \\
3. & Atbara & Atbara & 180 & 75 & 11.1 \\
4. & Blue Nile & Khartoum & 330 & 138 & 48.3 \\
5. & White Nile & Khartoum & 1730 & 722 & 26.0 \\
7. & Sudd wetland & Malakal & 35 & 14 & 16.1 \\
\hline
\end{tabular}

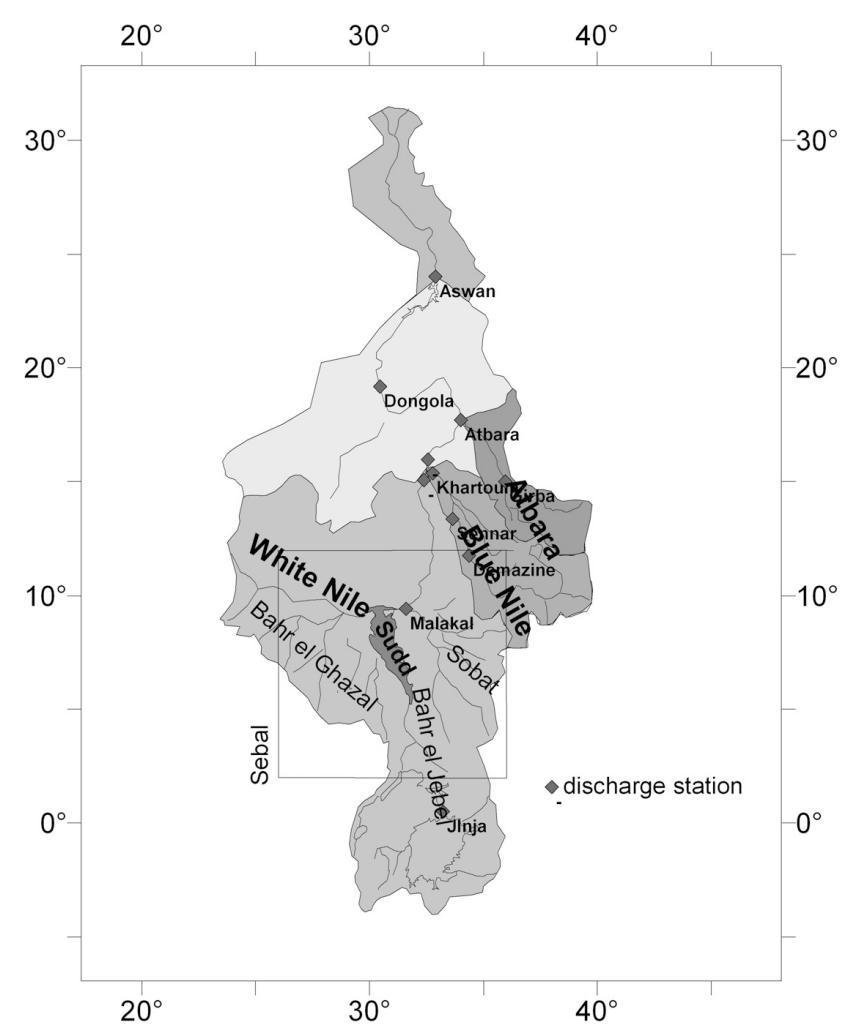

Fig. 3. Sub-catchments of the Nile and the discharge gauging locations.

\subsection{Hydrology and water resources}

The Nile starts from lake Victoria (in fact from farther south at the Kagera River feeding the lake) and travels north, receiving water from numerous streams and lakes on both sides (Figs. 1, 2 and 3). In the Sudd, where it takes the name of Bahr el Jebel, the river spills its banks, creating huge swamps where more than half of the river inflow is evaporated. At Lake No, east of Malakal it is joined by the Bahr el Ghazal River draining the southwestern plains bordering the Congo Basin. The Bahr el Ghazal is a huge basin subject to high rainfall over the upper catchments, but with negligible con- tribution to the Nile flows. The Sobat tributary originating from the Ethiopian Plateau and partly from the plains east of the main river joins Bahr el Jebel at Malakal. Downstream this confluence (where it is called the White Nile), it travels downstream a mild slope up to the confluence with the Blue Nile at Khartoum. The Blue Nile originates from Lake Tana located on the Ethiopian Plateau at $1800 \mathrm{~m}$ above MSL, and in a region of high summer rainfall $(1500 \mathrm{~mm} / \mathrm{yr})$. The only main tributary of the Nile before it ends up at the Mediterranean Sea is the Atbara River, also originating from the Ethiopian Plateau. The flows originated from the Ethiopian Plateau are quite seasonal and with a more rapid response compared to the flow of the White Nile coming from the Equatorial lakes. Further details on the Nile hydrology can be found in Shahin (1985), Sutcliffe and Parks (1999) among others.

The river catchments of the Nile tributaries were delineated based on the Digital Elevation Model DEM and the drainage maps of the riparian countries. The catchments areas and average annual flows are given in Table 1 and Fig. 3.

Ten countries share the Nile River: Burundi, Congo, Egypt, Eritrea, Ethiopia, Kenya, Rwanda, Sudan, Tanzania and Uganda. The Nile water is vital to the dry countries downstream (Egypt and Sudan), where historically intensive irrigation development exists, and still continues, imposing increasing demands on the Nile water. The upstream countries rely less on the Nile waters, although new water resources projects commenced in some of the upstream countries. Due to the seasonal nature of the Nile flow, several dams were built to control the Nile water for irrigation and hydropower generation. The huge regulation of the flows at Aswan dam constitutes a significant intervention in the natural hydrological cycle, so that it is more appropriate to consider the outflow from the basin at Dongola station (immediately upstream of the Aswan reservoir), rather than at the Mediterranean Sea. 


\section{The regional climate model}

\subsection{RACMO basic features}

The Regional Atmospheric Climate Model (RACMO) is a limited area model of the atmospheric and land surface processes. It is based on the HIRLAM (HIgh Resolution Limited Area Model) weather forecasting system in combination with the physical parameterisation from the ECMWF model (Lenderink et al., 2003). It is the main limited area model used by KNMI (The Royal Netherlands Meteorological Institute) for climate research. The physical processes of: radiation, convection, orography, turbulence and land surface, schematised in Fig. 4, are parameterised by different schemes to simulate those processes. Of particular interest is the formulation of the land surface scheme in RACMO, the so-called Tiled ECMWF Scheme for Surface Exchanges over Land (TESSEL; van den Hurk et al., 2000). Each land grid box is composed of 6 tiles representing various fractions of bare ground and vegetation. The soil below the surface is composed of 4 layers with fixed depths being 0.07, 0.33, 1.27 and $3.32 \mathrm{~m}$ thickness, respectively, following Lenderink et al. (2003). The soil physical properties are uniform for all model grids. The precipitation on a grid box is partitioned into interception and throughfall. The interception is a function of the type of rain (convective, large scale) and the Leaf Area Index LAI. The throughfall infiltrates into the soil, where vertical water exchange obeys Darcy's law through the 4 soil layers. Turbulent fluxes (sensible and latent heat) are computed based on resistance parameterisation of the respective tiles (open water, bare soil, vegetative cover) that represent surface and aerodynamic properties and the soil moisture conditions. The remaining net heat flux is transferred to the soil. Surface runoff occurs when the throughfall exceeds the infiltration capacity (this rarely occurs). The main runoff component is the deep runoff through the bottom of the 4th soil layer (i.e. free drainage). The original RACMO model doesn't provide routing of runoff to the catchment outlet. Further details of these parameterisation schemes can be found at http://www.ecmwf.int/research/.

The RACMO model has been used and verified extensively for climate studies in Europe (Lenderink et al., 2003) and Antarctica (Lipzig et al., 1998). In particular for the European climate studies, it is shown to adequately represent the mean annual cycle and daily variability of precipitation and near surface temperature. In this domain the model has a tendency to underestimate the convective fraction of the total precipitation, but the general signature of the hydrological cycle on sub-continental scale is adequate, provided that the input from the lateral boundaries is realistic. This is ensured when re-analysis data like the ECMWF 40 year reanalysis (Simmonds and Gibson, 2000) are used.

The RACMO skill to simulate the hydroclimate in the Nile area has never been established. In this study, we focus on simulations covering a period between 1995 and

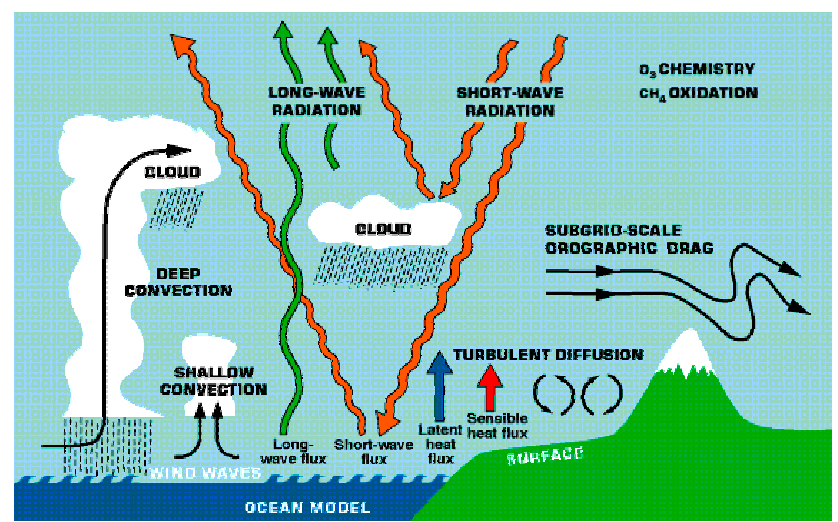

Fig. 4. Schematic representation of the structure of TESSEL land surface scheme (Source IFS, p. 104).

2000, where initial and lateral boundary conditions are taken from ERA40. The model is run in the domain between $12^{\circ} \mathrm{S}, 35.96^{\circ} \mathrm{N}$ and $10^{\circ} \mathrm{E}$ to $54.44^{\circ} \mathrm{E}$ (Fig. 1 ), at $0.44 \times 0.44^{\circ}$ $\left(\sim 50 \times 50 \mathrm{~km}^{2}\right)$ resolution.

The vegetation cover was retrieved from the GLCC Global Land Coverage Characteristics dataset as classified to the TESSEL land surface scheme. The remaining surface parameters (geo-potential height, orographic variability) were interpolated from the HIRLAM climate system.

\subsection{Model adjustments}

Several 1-year model runs were performed to define the necessary adjustment of RACMO to the Nile conditions. First, inspection of the ECMWF physics based on the GLCC maps shows that the Sudd, and some areas farther north have been classified as 'bogs', to which a very high minimum canopy resistance $\left(r_{\mathrm{s}, \min }=240 \mathrm{~s} / \mathrm{m}\right)$ is assigned (van den Hurk et al., 2000). This is unrealistic for the typical wetlands vegetation over the Sudd (e.g. Lafleur and Rouse, 1988). Results were improved after replacing the land cover characteristics of the GLCC with ECOCLIMAP (Masson et al., 2003). The canopy resistance $r_{\mathrm{s}, \min }$ over the Sudd is reduced to $15 \mathrm{~s} / \mathrm{m}$ to mimic the wetland evaporation characteristics.

A specific characteristic in the Nile Basin is the wide spreading of the river flow over the Sudd swamps. Since RACMO doesn't include the runoff routing process, this had to be introduced by explicitly transferring the runoff from the upstream catchment to the Sudd. Every day during the model simulation, an additional amount of water stemming from the upstream runoff is distributed equally over the 15 grid points of the Sudd. A spin up time of 1 year is used to approach a realistic initial soil moisture condition.

Evaluation of the radiation results against field measurements (from two meteorological stations) showed that the default radiation parameterization underestimates the incoming short wave radiation, while it computes realistic incoming long wave radiation. This could be corrected by adjusting 


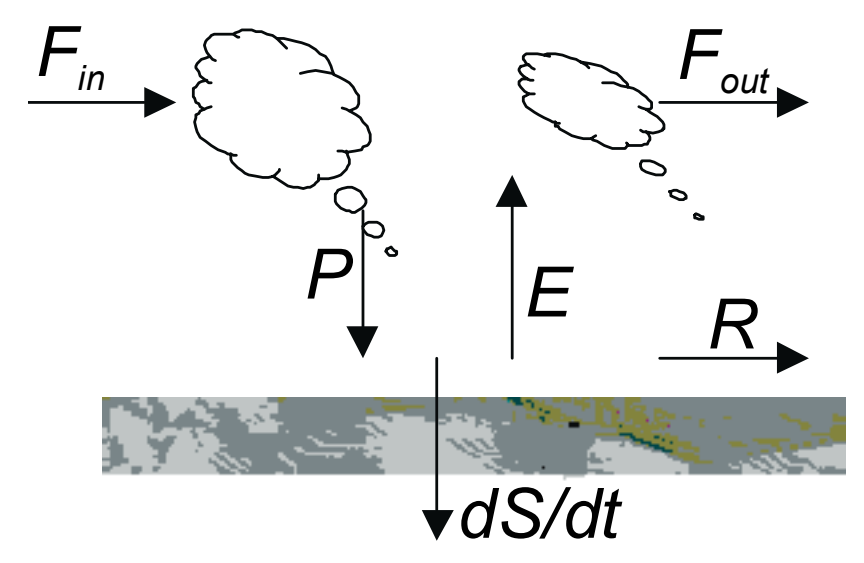

Fig. 5. The components of a regional water cycle.

the amount of aerosols. In addition, over the Ethiopian highlands, the model originally computed unrealistically high precipitation. After smoothing the orography, this was substantially improved. Unrealistically high river runoff was obtained by the default drainage coefficients, and reasonable estimates were obtained when the saturated hydraulic conductivity was reduced by a factor 10 to represent more accurately the character of flooded alluvial soils. The results presented hereafter are based on these modifications.

\subsection{Nile water cycle}

The regional water cycle over the Nile basin, i.e. both land surface (hydrological) and atmospheric components can be characterized (qualitatively) at the basin level using parameters such as moisture recycling ratio, feedback ratios, precipitation efficiency and moistening efficiency. The moisture recycling in a region is the process by which evaporation from the region contributes to precipitation in the same region. The precipitation " $P$ " over a region can be de-composed into two components $P_{l}$ (local) and $P_{a}$ (advective). The advective atmospheric moisture that generates $P_{a}$ can be either of oceanic and/or land evaporation source. The recycling ratio $\beta$ is defined as $P_{l} / P$, i.e. the ratio of locally generated precipitation to total precipitation. Different methodologies exist to compute the moisture recycling, ranging from simple water balance models (Budyko, 1974; Eltahir and Bras, 1994; Savenije, 1995; Schär et al., 1999) to detailed modeling studies of water particle tracking (Koster et al., 1986; Bosilovich and Schubert, 2002). A review of the precipitation recycling formulae and their mutual comparison is given in Brude and Zangvil (2001), Brubaker et al. (1993) and others. Different sources of fluxes data are used; observations, re-analysis, and model results. Figure 5 shows the components of the regional water cycle, where $F_{\text {in }}$ and $F_{\text {out }}$ are the inward and outward atmospheric fluxes, $P$ precipitation, $E$ evaporation, $R$ runoff and $d S / d t$ is the interaction with sub-surface water.

For the Nile basin we have computed moisture recycling using the formula of Budyko (1974) extended by Brubaker et al. (1993), and given by:

$\beta=\frac{P_{l}}{P}=\frac{E}{E+2 F_{\text {in }}}$

Two basic assumptions were introduced in the derivation of Eq. (1): the evaporated moisture and atmospheric moisture are well mixed, and the vertical moisture fluxes $E, P_{a}, P_{l}$ are static and equal to their average values in the region. The bulk recycling formula of Eq. (1) is scale dependent, i.e. theoretically it is equal to 1 for the whole globe and reduces to zero for a point location. In the literature different "flavours" of the recycling formula exist. E.g. Schär et al. (1999) defined recycling ratio as $\beta=E /\left(E+F_{\text {in }}\right)$. Eltahir and Brass (1994) derived $\beta$ on a control volume (local model grid), and over the whole region their formula can be approximated to that of Schär et al. (1999). Savenije (1995), based on a Lagrangean approach defined a moisture feedback ratio $\gamma$ as the moisture supplied to the atmosphere by evaporation during the wet season " $E_{w}$ " relative to precipitation Eq. (2). Here the evaporated moisture is not necessarily precipitating back within the same region.

$\gamma=\frac{E_{w}}{P}$

It should be stressed that precipitation recycling derived by a regional average formula like Eqs. (1) or Eq. (2) serves as a diagnostic measure of the regional land surface-climate interaction. It can be a useful index to compare different basins of the world, but it has no prognostic value. The embedded assumptions in those formulae - well mixing and linear variability of fluxes - render them incapable of computing impact of land use changes on climate. Obviously, the land surface-climate interactions are highly dynamic and nonlinear processes. Only with comprehensive climate modeling simulations it may be possible to obtain a better understanding of these (two way) interactions processes.

It may be interesting to introduce two more ratios; the precipitation efficiency " $p$ " and the moistening efficiency " $m$ ". $p$ is defined as the amount of precipitation in a given region relative to the atmospheric moisture flux overhead, given by:

$p=\frac{P}{F}$

Similarly $m$ is defined as the amount of regional evaporation relative to the atmospheric moisture flux (Trenberth, 1999), given by:

$m=\frac{E}{F}$

Different definitions for precipitation efficiency also exist in the literature. Schär et al. (1999) defined the denominator of Eq. (3) as the total incoming moisture in a region $\left(E+F_{\text {in }}\right)$ instead of the mean flux. It is to be noted that $\gamma=m / p$, when evaporation is negligible outside the wet season, i.e. when $E_{w}=E$. 


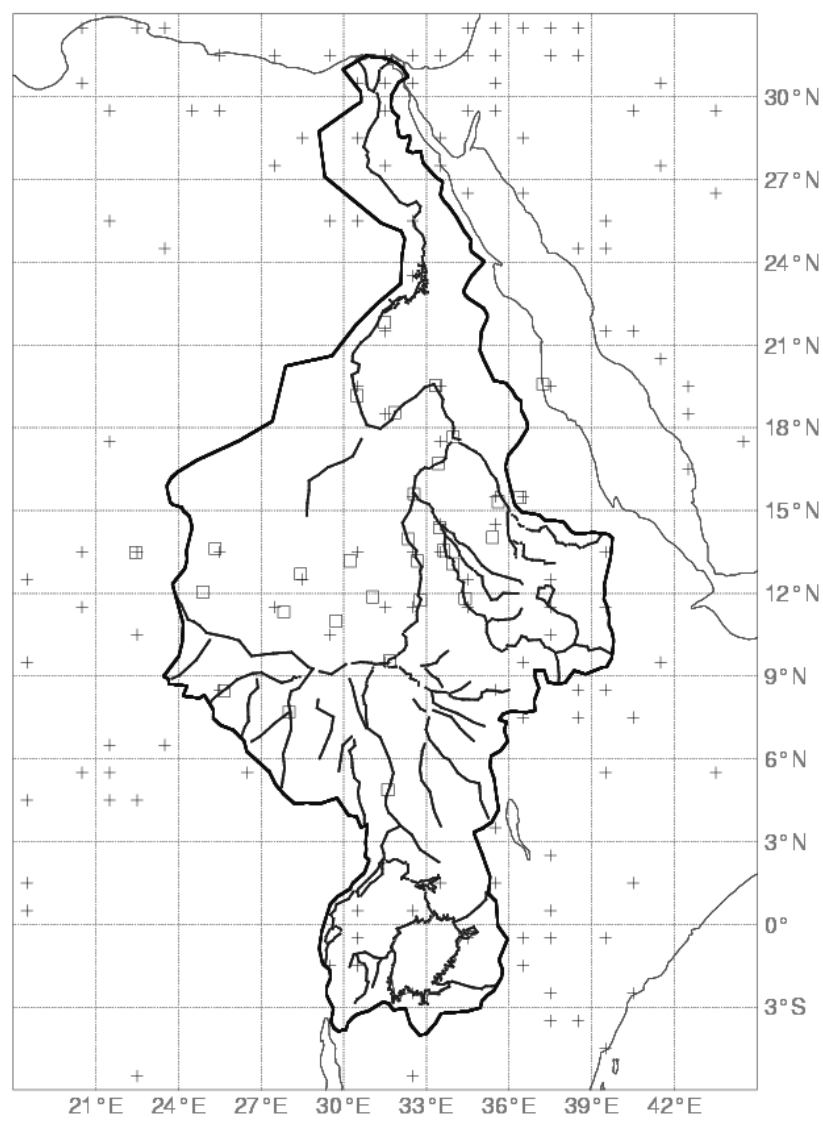

Fig. 6. Location of the precipitation stations (+ GPCC, Sudan gauging stations).

\section{Observations}

The observational datasets used for assessing model output include: ground stations of meteorological data, satellite derived estimates of evaporation, precipitation and river discharge data.

\subsection{River discharge data}

Reliable discharge measurements are available at 11 key locations along the Nile River system (Fig. 3). The water balance of the different river reaches allows inspection of the flow time series and estimation of the irrigation abstractions and/or the evaporation from storage reservoirs. The climate model computes natural river flows as the sum of all upstream free drainage fluxes. Therefore, the measured gauged flows were corrected for withdrawals and evaporation losses occurring between the percolation and the location of the meteorological station to derive natural river flows at the outlet of the sub-basins. Inspection of the river discharge data shows also - for comparison between model results and observations on a monthly time scale - that no correction for travel time was deemed necessary.

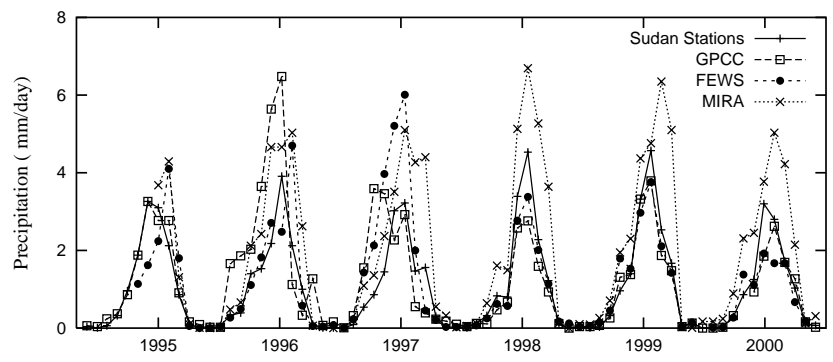

Fig. 7. Comparison of precipitation from 4 sources: Sudan stations, GPCC, MIRA and FEWS; (mean of the 30 point locations of the Sudan stations).

\subsection{Precipitation data}

Four sources of precipitation data have been considered: (i) The Sudan meteorological department ground stations data, (ii) The Global Precipitation Climatology Center (GPCC), providing monthly rainfall data at $1^{\circ}$ resolution, interpolated from conventional gauged observations (Rudolf et al., 2003), the data are available at http://www.dwd.de/ en/FundE/Klima/KLIS/int/GPCC/. (iii) The Famine Early Warning System (FEWS), providing 10-daily rainfall data at $0.1^{\circ}$ resolution, based on METEOSAT 5 satellite data, gauged data and modeled data (Herman et al., 1997), the data are available at http://www.cpc.ncep.noaa.gov/products/ fews/data.html. (iv) The MIRA (Microwave Infrared Algorithm) data combining satellite passive microwave and infrared data to produce daily means precipitation at $0.1^{\circ}$ resolution (Todd et al., 2001). Figure 6 shows the locations of GPCC and the Sudan stations. No station data were available from the other riparian countries.

A rigorous inspection has been done for the daily data of the Sudan gauging stations, which were aggregated to monthly values. This dataset is considered as reference for the comparison with the other datasets. The average values for the 30 point locations of the Sudan stations are presented in Fig. 7. Note that GPCC and Sudan stations are supposed to be from the same source, i.e. gauged data of the Sudan meteorological department. The two curves are not identical, but indeed closest, except in 1996. Differences may be attributed to the fact that the GPCC data pass an automatic quality control. No further details are available on how the GPCC data has been corrected and averaged. The MIRA data is generally about $50 \%$ higher than all 3 datasets, probably due to the inclusion of the radar data. Except for a few months, the FEWS dataset (as expected) is close to GPCC. The Root Mean Square Error (RMSE) in the rainfall datasets: GPCC, FEWS and MIRA against the reference dataset are: $0.87,0.86$ and $1.33 \mathrm{~mm} /$ day, respectively. The correlation coefficient are: $0.77,0.82$ and 0.91 , respectively. The results show that although MIRA has a high correlation coefficient, it also has a high RMSE. The GPCC and FEWS datasets have 
the same order of magnitude values both for RMSE and correlation coefficient. The GPCC dataset is used for the evaluation of model results, owing to its fair comparability to the reference dataset (except in 1996) and the spatial extent of the data.

\subsection{Evaporation data}

The hydrometeorological observations over the Upper Nile swamps are very scarce (the area has been a war zone since 1983). Remote sensing based estimates can be instrumental to fill in the gaps of hydrological knowledge. Therefore, NOAA-AVHRR LAC (National Oceanic Atmospheric Administration-Advanced Very High Resolution Radiometer Local Area Coverage) images were acquired over an area of $1000 \times 1000 \mathrm{~km}^{2}$, covering the swamps of the Sudd, the Bahr el Ghazal and the Sobat basins indicated by the "Sebal area" in Fig. 3. The resolution of the images is $1 \mathrm{~km}$. Monthly evaporation maps were derived using the SEBAL algorithm (Bastiaanssen et al., 2002). SEBAL is a parameterization scheme of the surface heat fluxes based on spectral satellite measurements. Monthly (actual) evaporation, evaporative fraction and soil moisture maps were prepared for 3 years of different hydrometeorological conditions 1995, 1999 and 2000. Evaporation is computed as the multiplication of evaporative fraction and the net radiation at the surface. The net short wave radiation and net long wave radiation were computed based on short wave transmittance through the atmosphere. The amount of soil moisture in the root zone ( $\sim 1 \mathrm{~m}$ of the top soil layer) is determined empirically from the evaporative fraction (Scott et al., 2003). The evaporation computed from SEBAL has been validated by checking water balance computations of 3 sub basins: Sudd, Bahr el Ghazal downstream discharge stations and Sobat (Mohamed et al., 2004). Acceptable results were obtained for the Sudd and Sobat, while the balance doesn't close for the Ghazal Basin. This is due to the underestimated surface inflow to this swamp. There is no information to evaluate the SEBAL evaporation for the areas outside these 3 sub-basins.

\subsection{Radiation data}

Only few radiation measurements are available within the model domain. Sunshine duration is available for the Sudan stations, which is routinely used to calculate solar radiation. Observed radiation data at two stations could be acquired: Riyadh (Saudia Arabia) at $24.7^{\circ} \mathrm{N}, 46.7^{\circ} \mathrm{E}$ and Ndabibi (Kenya) at $0.5^{\circ} \mathrm{S}, 36.2^{\circ} \mathrm{E}$. They are located outside the basin, but within the model domain. The Riyadh data are archived at the World Radiation Monitoring Center WRMC, the data center of the Baseline Surface Radiation Network, available at http://bsrn.ethz.ch/. At the Ndabibi station, measurements of the incoming short wave radiation for 1998 at 20-min interval are available (Farah, 2001).

\section{Model results and discussion}

Since the sub-basins of the Nile have different physical and hydroclimatological characteristics, it is noteworthy to evaluate model results over both the whole Nile basin (Main Nile) and the sub-basins separately. Monthly time series results (1995 to 2000), or mean annual cycles are presented for the Sudd basin, White Nile, Blue Nile, Atbara River and the Main Nile (locations shown in Fig. 3). The results presented constitute: runoff, precipitation, evaporation, soil moisture storage, radiation and moisture recycling. A monthly time step has been used to smoothen out irregularities of the climate fields, which exist at high temporal resolution both in sample observations and model results. Considering the overall objective of the modeling exercise (sensitivity study) a monthly time step was considered acceptable.

\subsection{Runoff}

Model runoff $R$ is compared to the river discharge gauged at catchment outlets of the 4 sub-basins Atbara, White Nile, Blue Nile and the Main Nile (Fig. 8). The location of the subbasins and discharge measuring stations is given in Fig. 3. Values are expressed in $\mathrm{m}^{3} / \mathrm{s}$, to allow inspection of the relative contribution of each sub-basin to the total flow at Aswan. It is to be noted that RACMO computation doesn't include groundwater flow below the $5 \mathrm{~m}$ depth, i.e. the calculated $R$ may include a groundwater recharge term, which believed is to be small and can be neglected. The model overestimates $R$ over the White Nile, and hence on the Main Nile. The results over the Ethiopian Plateau (Atbara and Blue Nile) are reasonably well in magnitude and time evolution. It is to be noted that a small error, e.g. on precipitation and/or evaporation over the White Nile can result in an excessive error of runoff because of its extremely low runoff coefficient. E.g. an error of $P$ of $0.2 \mathrm{~mm} /$ day produces an error of about $4000 \mathrm{~m}^{3} / \mathrm{s}$ in runoff. The mean annual runoff coefficient $R / P$ of observed $P$ and $R$ in 1995 to 2000 for the Main Nile, Atbara, White Nile and the Blue Nile are 0.05, $0.16,0.02$ and 0.19 , respectively, and the corresponding results derived from the model are 0.14, 0.17, 0.09 and 0.29. While tuning the model, we were more inclined to obtain optimal results over the Atbara and Blue Nile catchment rather than the White Nile since about 5/7 of the Nile runoff is generated from these two catchments. The RMSE of runoff for the 4 sub-basins: Nile, Atbara, White Nile and Blue Nile are $3836,340,2011$ and $1754 \mathrm{~m}^{3} / \mathrm{s}$, respectively.

\subsection{Precipitation}

The comparison of the mean model precipitation $P$ against observations of the GPCC is given in Fig. 9. On the Ethiopian catchment (Atbara and Blue Nile) - where most of the Nile runoff is generated - the model produced reasonable results, except for the rain peak on the Blue Nile, where the model 

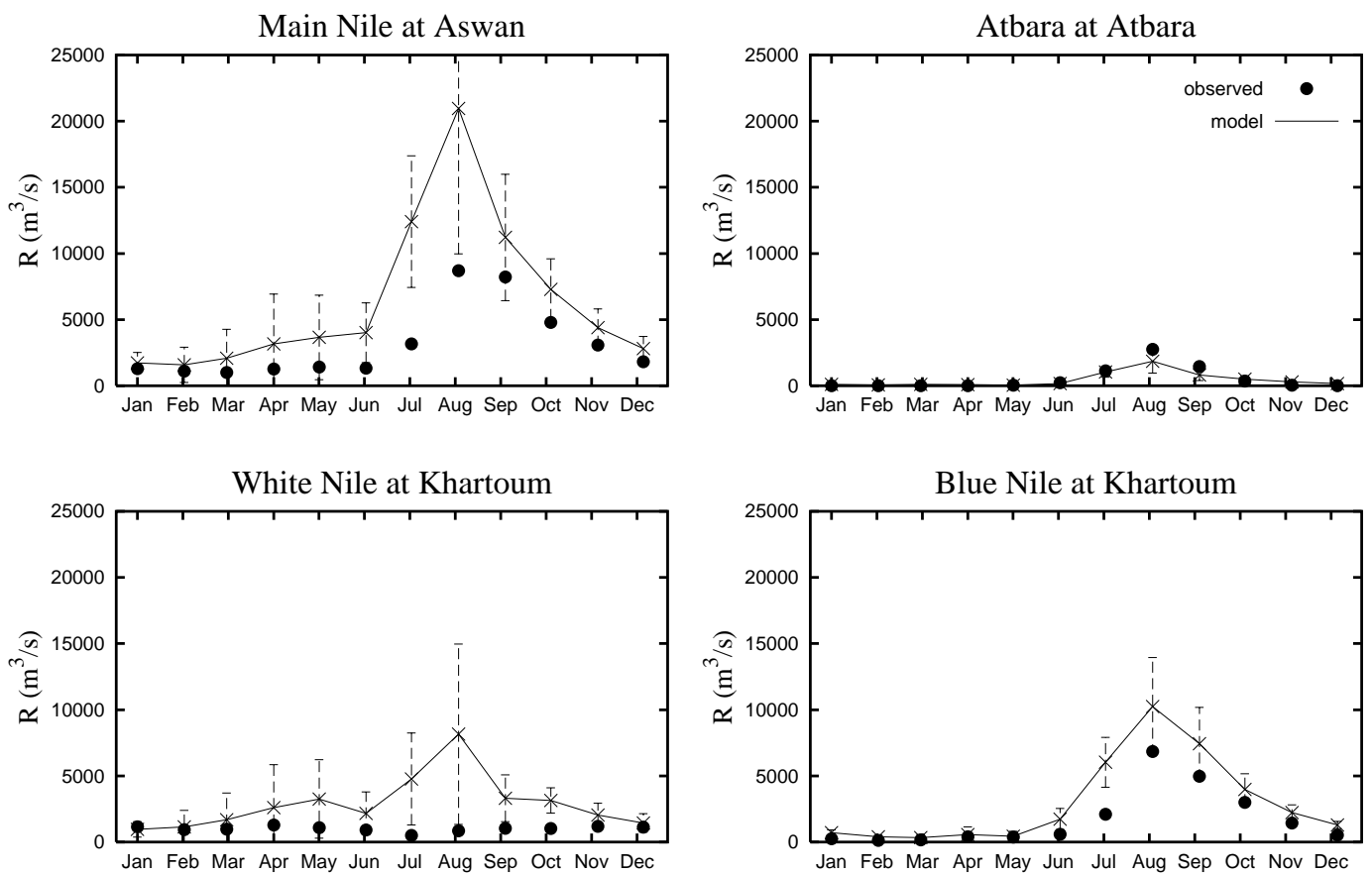

Fig. 8. Monthly model and observed runoff $R$ (mean annual cycle 1995 to 2000). Error bars indicate one standard deviation (std) of the monthly means.

Main Nile

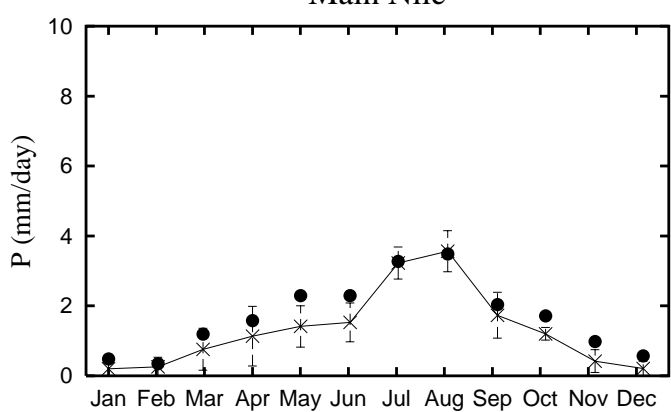

White Nile

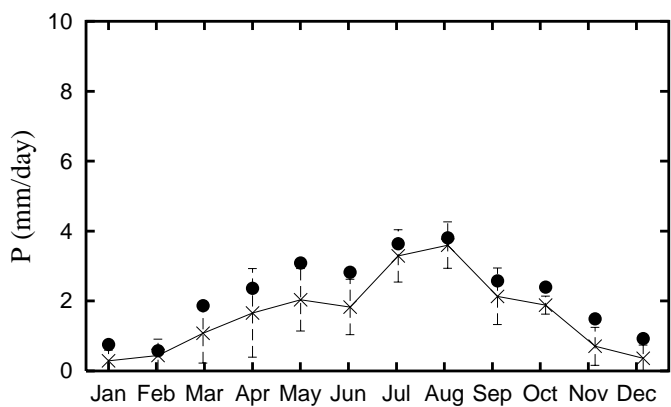

Atbara

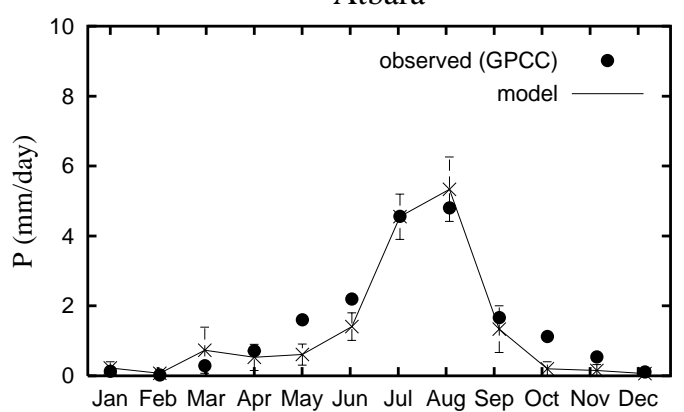

Blue Nile

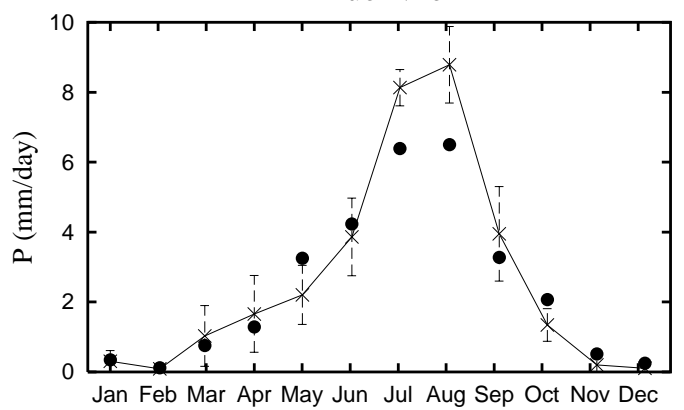

Fig. 9. Monthly model and observed (GPCC) precipitation $P$ (mean annual cycle 1995 to 2000). Error bars indicate one std of the monthly means.

slightly overestimates precipitation. The model accurately captures seasonality of the rains over the 4 sub-basins. On the White Nile the model underestimates the rain during the period from March to June. The RMSE of precipitation for the 4 sub-basins: Nile, Atbara, White Nile and Blue Nile are $0.47,0.52,0.65$ and $0.95 \mathrm{~mm} /$ day, respectively. 
(a) GPCC

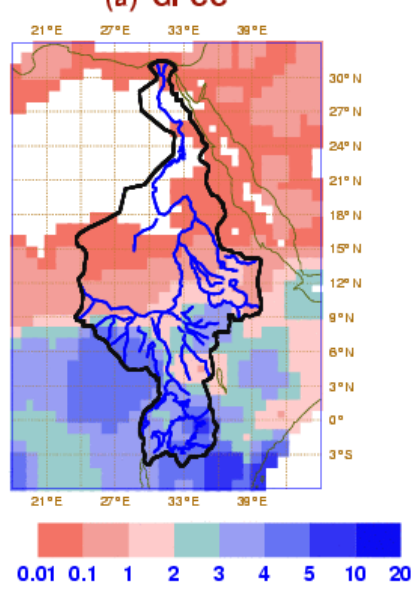

(b) ERA-40

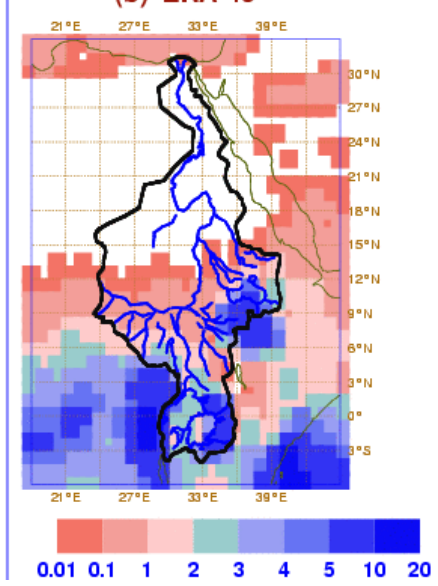

(c) RACMO

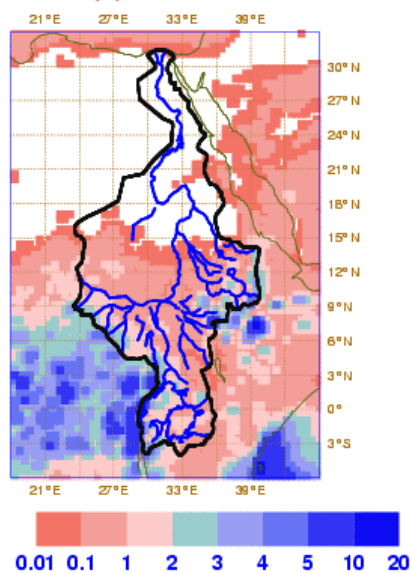

Fig. 10. Map results from March to May of 1999 precipitation in mm/day GPCC, ERA-40 and RACMO model.

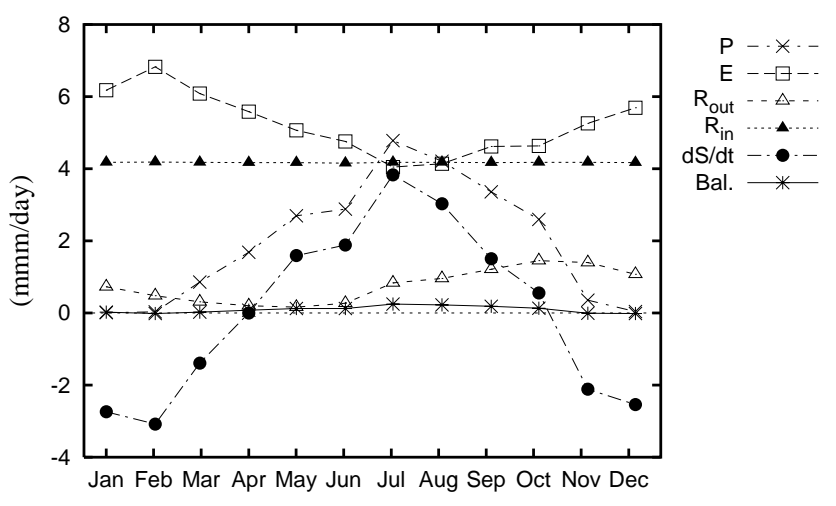

Fig. 11. Hydrological balance over the Sudd wetland in $\mathrm{mm} /$ day computed with the calibrated RACMO model (mean annual cycle 1995 to 2000).

Further inspection of the seasonal precipitation during a sample year of 1999, from March to May over the White Nile reveals that the underestimation is also present in the ERA-40 data. The RACMO bias is likely related to the lateral forcing imposed on the southern boundary of the model (Fig. 10). The ERA-40 places the (March to May) precipitation more south of the Bahr el Ghazal Basin than the GPCC data. RACMO computes compatible results to the reanalysis data, although the negative bias seems to be a bit more pronounced.

\subsection{Sudd water balance components}

To simulate the inundation of the Sudd by Nile water, a constant inflow $R_{i n}=4.1 \mathrm{~mm} /$ day is distributed every day over the 15 grid points of the Sudd. The $4.1 \mathrm{~mm} /$ day is the observed runoff from the Nile catchment upstream the Sudd, and it is a major evaporation source in the dry winter season. Fig. 11 shows a closed water balance derived from model re- sults over the Sudd, where Bal. $=P+R_{\text {in }}-R_{\text {out }}-E-d S / d t$. The term $d S / d t$ is the change of sub-surface water storage (soil moisture) in the 4 soil layers. The data represent the mean annual cycle for the 6 years 1995 to 2000 .

The comparison of model results to observations $P, E$, $R_{\text {out }}$ and $d S / d t$ is given in Fig. 12. In this case the model $d S / d t$ is computed for the top 2 layers ( $0.4 \mathrm{~m}$ thick), to allow comparison with $d S / d t$ estimated from remote sensing by SEBAL. The data represent a mean annual cycle for the 3 years: 1995, 1999 and 2000. In general, except for the dry months, the model reproduces $P, E$ and $d S / d t$ fairly well. $E$ is overestimated during the dry months from November from to April, but closely resembles remote sensing data during the wet season from May to October. The model reasonably reproduces the variability of the soil moisture storage $d S / d t$. The model underestimates the outflow runoff $R_{\text {out }}$ by about $1.5 \mathrm{~mm} /$ day $\left(\sim 600 \mathrm{~m}^{3} / \mathrm{s}\right)$. The mismatch of the flow discharge from the Sudd area is small compared to the White Nile flow presented in Fig. 8. The RMSE for the water budget components over the Sudd are 0.86, 1.17, 1.09 and $0.03 \mathrm{~mm} /$ day, for precipitation, evaporation, runoff and change of soil moisture storage, respectively.

It appears that there is a clear seasonality in the model $E$ over the Sudd in response to the available energy and atmospheric demand (higher during the drier months), whereas the remote sensing data show a quasi-steady evaporation. This can partly be attributed to the seasonality of the surface resistance $r_{s}$ to evaporation. The Sudd system is now parameterized as one large floodplain, but during the dry season, not all land is flooded. Hence, land at little higher elevation dries out, which boosts up the $r_{s}$ and reduces the $E$ flux. The model assumes constant $L A I$ throughout the year, so it doesn't adjust the $r_{s}$ during the dry season (low $L A I$ ), while SEBAL accounts for variability of $r_{s}$ with $L A I$. Considering the objective of the modeling study, to investigate the impact of the Sudd wetland on the Nile hydroclimatology, in 

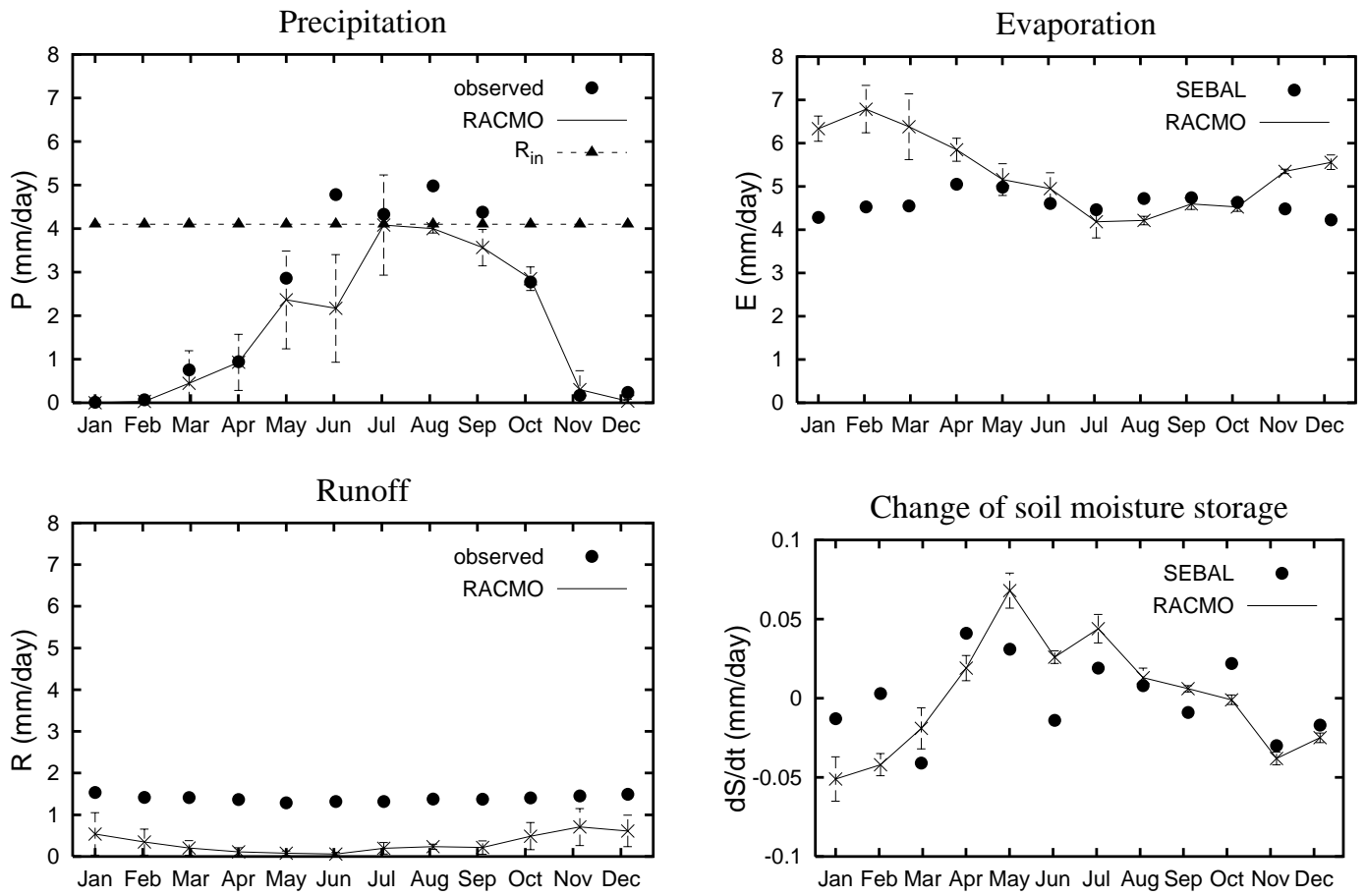

Fig. 12. Precipitation, Evaporation, Runoff and Soil moisture variation over the Sudd wetland (mean annual cycle: 1995, 1999, 2000). Error bars indicate one std of the monthly means.

particular during the rainy season, it is considered that model results are satisfactory.

\subsection{Radiation}

Incoming short wave $\left(R_{s d}\right)$ and long wave $\left(R_{l d}\right)$ radiation at the land surface observed at Riyadh and incoming short wave radiation $R_{s d}$ at Ndabibi are compared to model results in Fig. 13. In the original formulation of RACMO, $R_{s d}$ in Riyadh was underestimated by 20 to $40 \mathrm{~W} / \mathrm{m}^{2}$ ( $\sim 10$ to $20 \%$ ). To remove this bias, the climatological aerosols content was reduced, but from Fig. 13 it seems that the aerosol reduction has been slightly too strong. Note the difference in seasonal phasing of $R_{s d}$ between Riyadh at $24.7^{\circ} \mathrm{N}$ and $\mathrm{Nd}-$ abibi at $0.5^{\circ} \mathrm{S}$. Peak $R_{s d}$ at Riyadh occurs during the northern hemisphere summer associated with the lowest $R_{s d}$ at Ndabibi. The only available long wave radiation measurements at Riyadh shows that RACMO could reproduce $R_{l d}$ quite accurately. The RMSE in $\mathrm{W} / \mathrm{m}^{2}$ are $22,7.5$ and 21.2 for Riyadh short wave radiation, Riyadh long wave radiation and Ndabibi short wave radiation, respectively.

\subsection{Total Nile basin water cycle}

The time series of the regional water cycle components; $F_{\text {in }}$, $F_{\text {out }}, P, E, R, d S / d t$ over the Nile area are given in Table 2 . The data comprise the mean annual cycle of model results during 1995 to 2000 averaged over the whole Nile area. $P$,
Table 2. RACMO model results over the Nile Basin (Mean annual cycle 1995 to 2000 ) in $\mathrm{mm} /$ day.

\begin{tabular}{lcccccr}
\hline Month & $F_{\text {in }}$ & $F_{\text {out }}$ & $P$ & $E$ & $R$ & $d S / d t$ \\
\hline January & 5.16 & 5.62 & 0.63 & 0.96 & 0.11 & -0.40 \\
February & 4.93 & 5.32 & 0.62 & 0.94 & 0.10 & -0.36 \\
March & 6.29 & 5.93 & 1.38 & 1.11 & 0.16 & 0.11 \\
April & 6.44 & 5.72 & 1.73 & 1.31 & 0.21 & 0.20 \\
May & 5.88 & 5.66 & 1.61 & 1.44 & 0.17 & 0.01 \\
June & 5.17 & 4.99 & 1.39 & 1.26 & 0.14 & 0.03 \\
July & 5.63 & 4.47 & 2.38 & 1.51 & 0.28 & 0.60 \\
August & 5.70 & 4.77 & 2.76 & 1.77 & 0.45 & 0.49 \\
September & 5.58 & 5.42 & 1.84 & 1.66 & 0.31 & -0.14 \\
October & 5.51 & 5.31 & 1.84 & 1.50 & 0.29 & 0.02 \\
November & 5.31 & 5.42 & 1.32 & 1.26 & 0.21 & -0.20 \\
December & 5.21 & 5.61 & 0.79 & 1.03 & 0.14 & -0.36 \\
\hline
\end{tabular}

$E$ and $R$ are based on 6 hourly data, $F_{\text {in }}$ and $F_{\text {out }}$ are based on 12 hourly, and $d S / d t$ is based on daily data. The annual cycle of the fluxes is not as pronounced as for the smaller sub-catchments, however, net convergence occurs during the period from June to September, and divergence from December to March. Obviously, $P, E$ and $R$ are higher during convergence months, and reduced during divergence time. Subsurface storage (within the 4 soil layers) occured during the rainy months, and depleted during the dry months, resulting in a zero annual mean. 
(a) Riyadh $\mathrm{R}_{\text {sd }}$

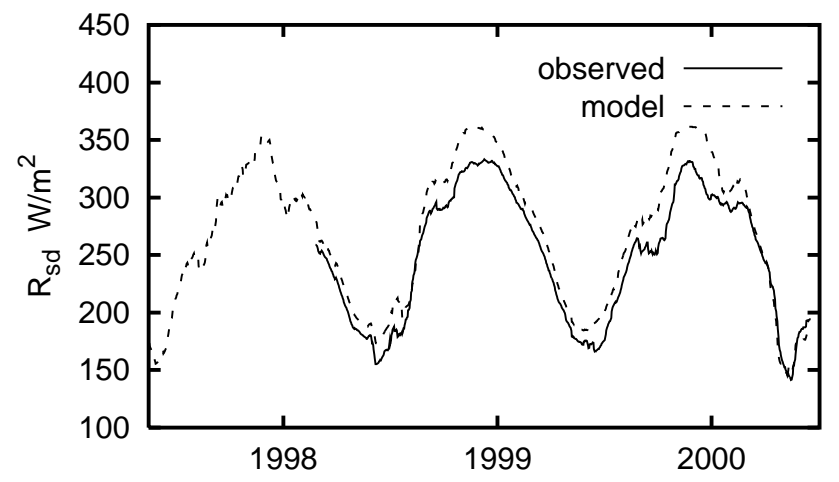

(b) Riyadh $\mathrm{R}_{\mathrm{ld}}$

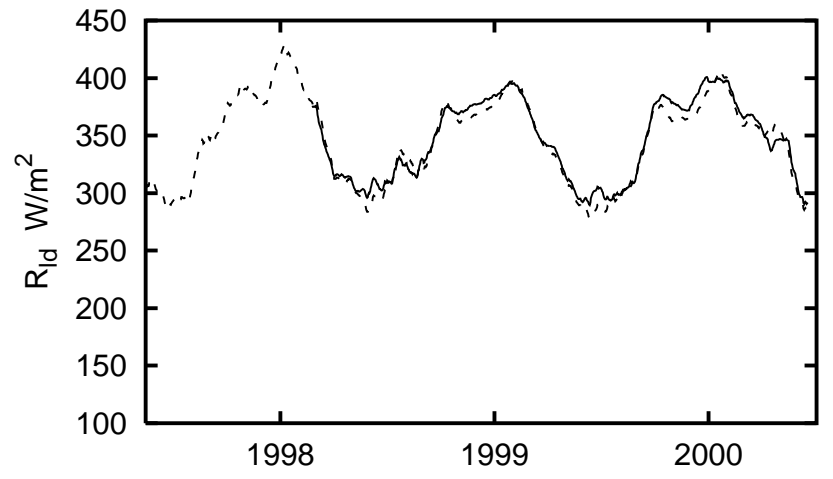

(c) Ndabibi $\mathrm{R}_{\mathrm{sd}}$

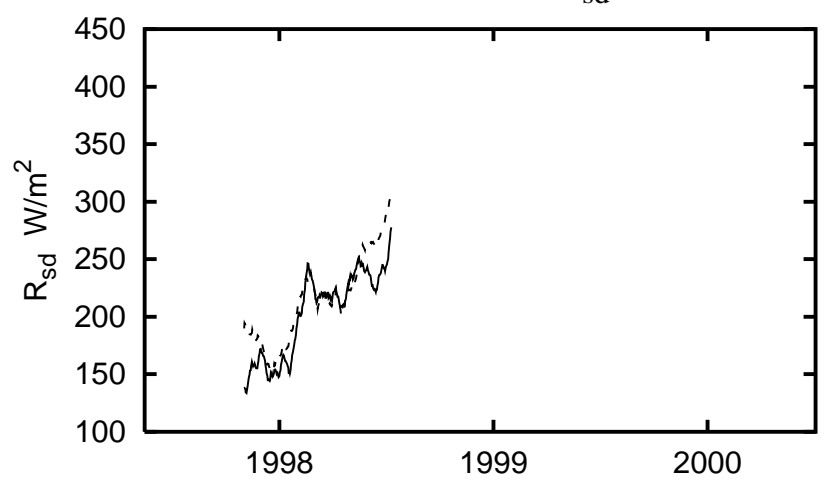

Fig. 13. Radiation results: (a) Incoming short wave radiation at Riyadh, (b) Incoming long wave radiation at Riyadh, (c) Incoming short wave radiation at Ndabibi (30 days moving average).

As discussed in Sect. 2, the Nile water cycle has both the characteristics of a single rainy season from June to September (Blue Nile and Atbara on the Ethiopian Plateau), and that of a double rainy season (part of the White Nile on the Equatorial Lakes Plateau). This is clearly depicted by Fig. 14, which shows the spatial distribution of the atmospheric horizontal water transport (arrows) and the water vapor convergence/divergence in the two distinct seasons: June to September, and December to March.
Over the Ethiopian Plateau, convergence occurs from June to September, with the direction of net moisture transport from the northeast, from the direction of the Red Sea and/or the Mediterranean. Detailed analysis of the moisture fields and wind patterns over the basin at low altitudes (up to $700 \mathrm{hPa}$ ) shows that from June to September, moisture over the Ethiopian Plateau is largely originated from the Atlantic Ocean, and to a lesser extent from the Indian Ocean, (results are not given here). Over the Red Sea relatively high moisture contents are limited to the lower levels (lower than $850 \mathrm{hPa}$ ). The wind patterns over the Ethiopian plateau, up to the $850 \mathrm{hPa}$ level, are from southwest, and it reverses direction from $700 \mathrm{hPa}$ upward (the so-called upper tropospheric tropical easterly jet). Clearly, the topography of the Ethiopian Plateau influences the vertical profile of the wind direction. A possible interpretation of the June to September convergence characteristics over the Ethiopian Plateau, is that moisture over the Plateau (mainly of Atlantic Ocean origin) is lifted up by orography and transported southwest by winds in the upper levels, producing a resultant net moisture transport into southwestern direction. This doesn't reject that there is moisture transport, at least from the southern part of the Red Sea towards the Ethiopian Plateau. Figure 14a also shows the strong southwesterly monsoon flow over the Somali coast (The Somali jet), a major carrier of atmospheric moisture toward India (Camberlin, 1997).

During the winter season from December to March, no convergence occur over the Ethiopian Plateau, in fact considerable divergence takes place.

The White Nile catchment, and in particular the Ghazal basin, displays a sizeable convergence from June to September, as well as the area just North of Lake Victoria. The Indian Ocean provides the major source of the summer time moisture in particular to the east of Bahr el Jebel, while the Atlantic moisture contributes to the precipitation over the Ghazal basin. During the winter season, the White Nile catchment acts as a divergence zone, with some convergence around lake Victoria. It is interesting to note that the convergence areas in Fig. 14 correspond to the runoff generating catchments. It is known that there is negligible contribution to the Nile flow downstream of these areas. E.g. the catchment within the Sudan territory has only a minor contribution to the Nile runoff. The spatial distribution of the convergence correlates well with the land topography (see Fig. 1).

The monthly precipitation recycling ratio $\beta$, precipitation efficiency $p$, and moistening efficiency $m$ computed by Eqs. (1), (3) and (4), respectively, are shown in Fig. 15. The seasonal feedback ratio $\gamma$ computed by Eq. (2) is given in Table 3. The data used in the 4 equations were derived from the Nile RCM. Although, the RCM is driven at the lateral boundaries by reanalysis data, it has the advantages that all regional climate processes are simulated, including the regional water transfer within the Nile domain. The Nile domain itself is much smaller than the RCM to be influenced by the lateral boundary conditions. On the other hand, the reanalysis data 

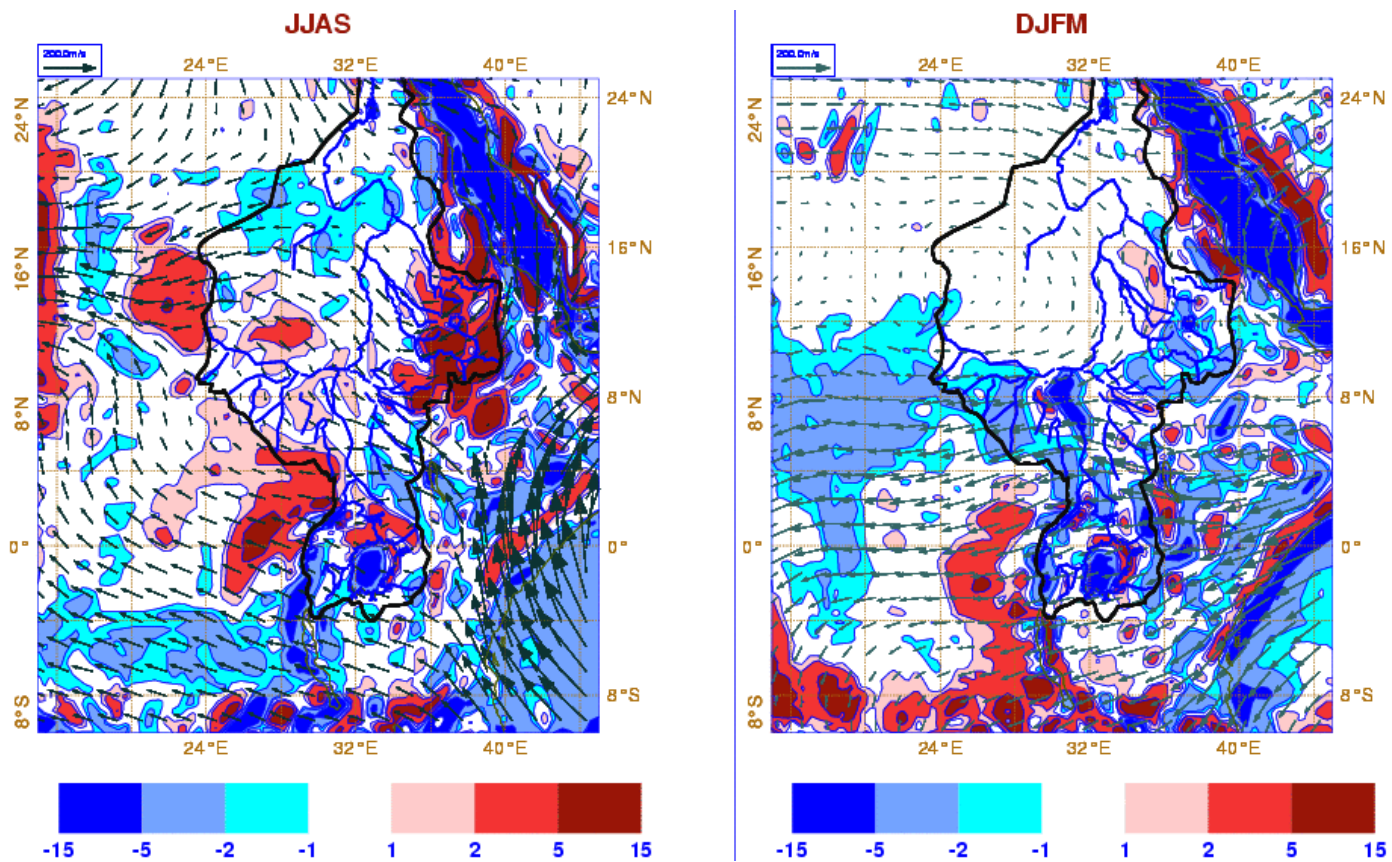

Fig. 14. Spatial distribution of atmospheric fluxes in $(\mathrm{kg} / \mathrm{m} / \mathrm{s})$ and convergence field in $\mathrm{mm} /$ day, for the two main seasons in $\mathrm{mm} / \mathrm{day}(+\mathrm{ve}$ is convergence and -ve is divergence). (a) wet season JJAS (from June to September), (b) dry season DJFM (from December to March).

are actually based on GCM simulations assimilated with observation. The resolution of the GCM might be too coarse to account for local (regional) processes, which could reasonably be captured by the RCM with much finer resolution.

Figure 15 shows that, in accordance with the seasonality of $P$ and $E$, both $p$ and $m$ and to some extend $\beta$ are relatively high during the rainy season. About $40 \%$ of the available atmospheric moisture in the basin precipitates during the rainy season from June to September, of which around $12 \%$ originates from local evaporation. The local evaporation contributes about $30 \%$ of the atmospheric moisture over the Nile during these months. The feedback ratio $\gamma$ during the rainy season reaches $74 \%$, approximately equal to $m / p$. Outside the rainy season, precipitation efficiency reduces to about $20 \%$ in December to March, whereas $F_{\text {in }}$ decreases only by about $10 \%$ in these months. Obviously a supply of $F_{\text {in }}$ alone is not sufficient to generate precipitation, a mechanism has to be present (see Sect. 2.1).

It is interesting to compare the annual water cycle over three main river basins: Amazon, Mississippi and the Nile (Fig. 16). A similar comparison for the Amazon and the Mississippi is given in Eltahir and Brass (1994). The data on the Amazon are based on ECMWF ERA-15 as reported in Eltahir and Brass (1994). The data of the Mississippi are based on observations reported in Benton et al. (1950). The data for the Nile Basin are based on the mean RACMO results 1995 to 2000 . The annual fluxes were normalized by the annual precipitation. The annual precipitation is $1950 \mathrm{~mm}$, $750 \mathrm{~mm}$ and $557 \mathrm{~mm}$ for the Amazon, Mississippi and the
Table 3. Parameters of the regional water cycle. *Upper limit values because $\gamma$ is defined as feedback during the rainy season only.

\begin{tabular}{lccc}
\hline & Amazon & Mississippi & Nile \\
\hline Moisture recycling $\beta$ & 17 & 8 & 11 \\
Feedback $\gamma$ & $58^{*}$ & $78^{*}$ & $86^{*}$ \\
Precipitation efficiency $p$ & 83 & 22 & 28 \\
Moistening efficiency $m$ & 48 & 17 & 24 \\
Runoff coefficient c & 42 & 22 & 14 \\
\hline
\end{tabular}

Nile, respectively. It is noteworthy that in the literature one may find different values of precipitation recycling over these basins, depending on data used, formula applied and size of the basin. In general, for the Amazon the value of $\beta$ varies between 24 to $50 \%$, while in the Mississippi it varies between 10 to $47 \%$ (Benton et al., 1950; Trenberth, 1999; Eltahir and Brass, 1994; Brubaker et al., 1993; Bosilovich et al., 2002). Using the mean annual data of Fig. 16, the precipitation recycling, feedback ratio, precipitation efficiency, moistening efficiency and runoff coefficient are summarized in Table 3.

Of the 3 basins, the Amazon shows the largest precipitation recycling within the catchment, followed by the Nile, and the Mississippi. Note that if the formula of Schär et. al. (1999) is applied to the same data, $\beta$ becomes $29 \%$, $14 \%$ and $19 \%$, for the Amazon, Mississippi and the Nile, respectively. Qualitatively, this implies that land surfaceatmosphere interaction is stronger in the Amazon than in the 


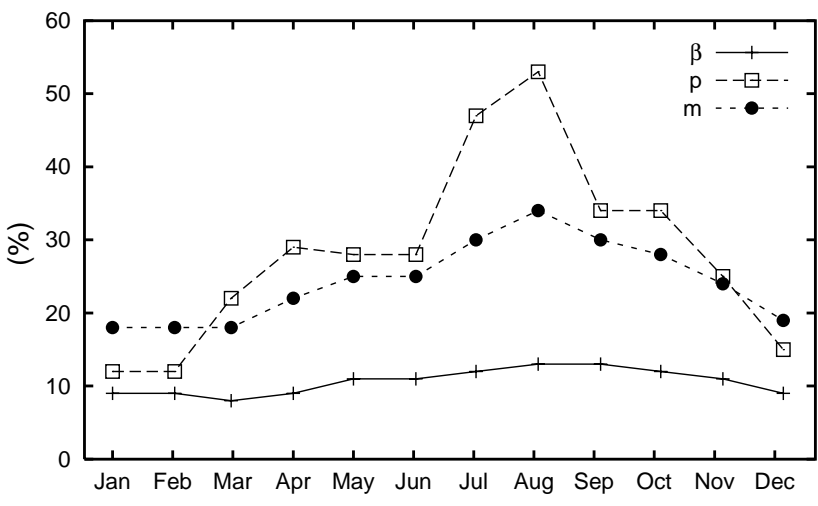

Fig. 15. Mean annual cycle of precipitation recycling $\beta$, precipitation efficiency $p$ and moistening efficiency $m$.

Nile and Mississippi, respectively. The same is true when considering the moistening efficiency.

Although the precipitation efficiency is also decreasing successively in the Amazon, Nile and Mississippi, runoff is not exactly following this sequence. The runoff ratio is the smallest in the Nile, due to the excessive evaporation in the swamps of the Sudd, Bahr el Ghazal and the Machar marshes. The ratio $F_{\text {out }} / F_{\text {in }}$ is $70 \%, 95 \%$ and $96 \%$ for the Amazon, Mississippi and Nile, respectively. Although this ratio is dependent on the large scale circulation in each basin, the barrier of the Indies Mountain Ranges is likely reducing the moisture outflow in the case of the Amazon.

\section{Summary and conclusion}

A regional climate model has been applied to the Nile Basin. The model has been customized to simulate the regional climate of the Nile (tropical, semi arid and arid climates). The exercise concentrates on reproducing the regional water cycle as accurately as possible. Observations on runoff, precipitation, evaporation and radiation have been used to evaluate the model results at the sub-basin level (White Nile, Blue Nile, Atbara and the Main Nile).

The model reproduces runoff reasonably well over the Blue Nile and Atbara sub-basins, while it overestimates the White Nile runoff. The extremely small runoff coefficient and huge catchment area of the White Nile makes the runoff very sensitive to inaccuracy of precipitation or evaporation. Except for the period March to June over the White Nile, the model simulates the precipitation well over the 4 sub-basins, in particular the time variation. The underestimation of precipitation on the White Nile from March to June is partly related to the ERA-40 forcing on the southern boundary of the model. The evaporation over the Sudd wetland could be accurately simulated during the rainy season, while it was overestimated during the dry months because permanent flooding is assumed. In fact, the largest part of the Sudd is a seasonal
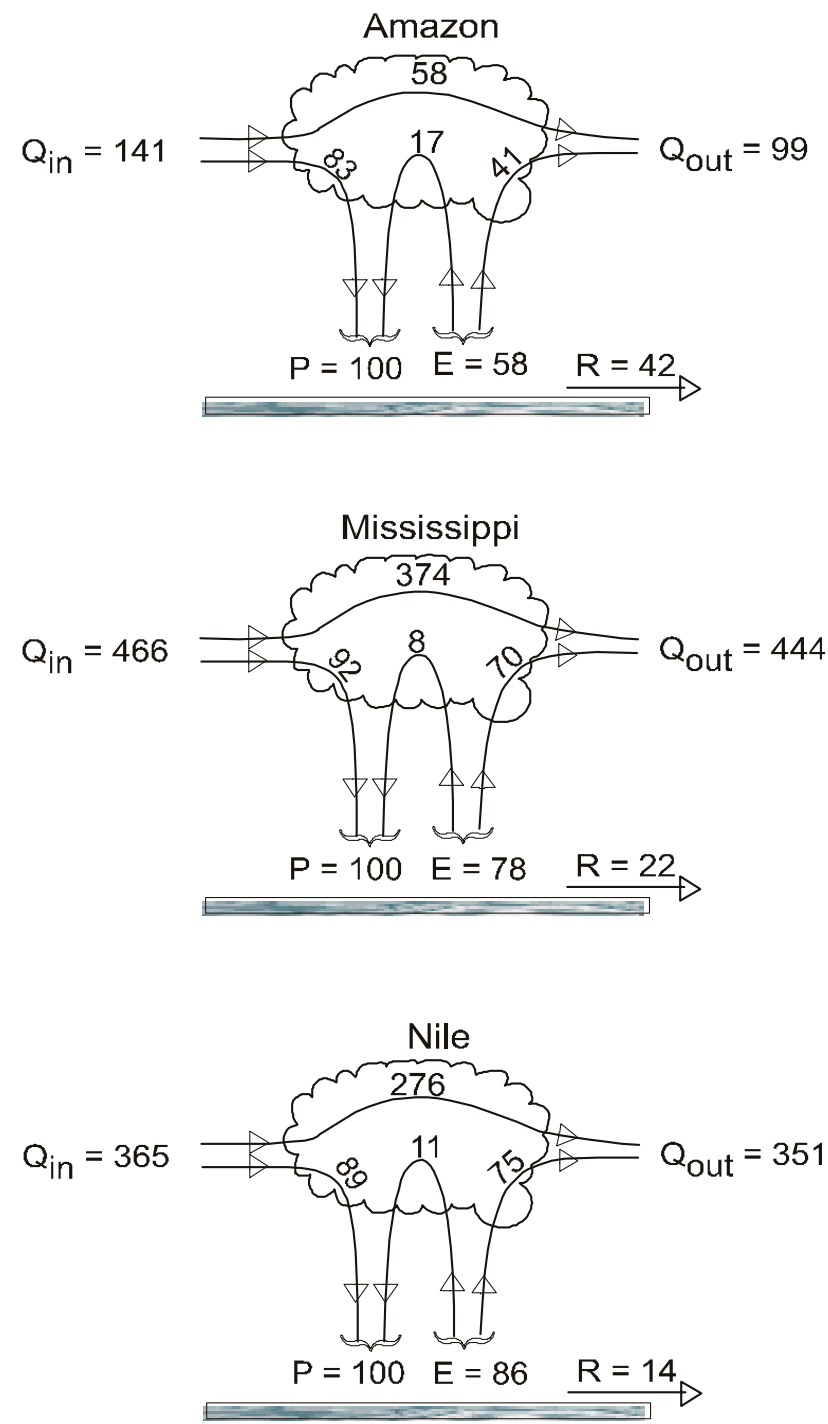

Fig. 16. Schematization of the regional water cycle over the Amazon, Mississippi and the Nile.

swamp. The soil moisture result over the Sudd is compatible with evaporation results, i.e. it closely resembles remote sensing derived estimates during the wet period, and it is underestimated during the dry months. Limited observations on radiation ( 2 stations) were compared to model results. The model overestimates the incoming short wave radiation for some months, while producing compatible results of the incoming long wave radiation.

Subsequently, the model has been used to compute the regional water cycle over the Nile Basin. The mean annual moisture recycling over the basin has been computed by the Budyko formula as $11 \%$; monthly values vary between 9 to $14 \%$. The annual results on the Nile water cycle have been compared to the Amazon and the Mississippi data given in the literature. The moisture recycling is 17,8 and $11 \%$ over 
the Amazon, Mississippi and the Nile, respectively, while the precipitation efficiency is 83,22 and $28 \%$, respectively. The annual runoff coefficient over the 3 basins is $0.42,0.22$, and 0.14 , respectively. This clearly shows that land atmosphere interaction over the Nile (and Mississippi) is much less pronounced as compared to the Amazon. Although the comparison between the 3 basins shows interesting conclusions on the relative water cycle components among the basins, the bulk recycling ratio alone is not sufficient to provide an indepth understanding of the land surface-climate interaction processes. These processes are dynamic, and highly nonlinear in nature. It is inaccurate to derive conclusions on the impact of regional precipitation based on, e.g. alteration of $\beta$. A more realistic approach to study the impact of land use changes on regional climate would be through applications of a sound RCM. In this particular case of the Nile, the same model has been used to simulate a dried wetland scenario, and to study the impact on regional hydroclimatology.

A regional atmospheric model calibrated against flow regimes and distributed remote sensing data is a strategic tool for understanding the impacts of climate change on water management and vice versa. In view of the growing problem of water scarcity, the demand for advanced atmospherichydrological tools - such as RACMO - is growing.

Acknowledgements. The material of this paper constitutes part of a larger research study on the moisture recycling over the Nile Basin funded by The International Water Management Institute (IWMI), The International Institute for Geo-Information Science and Earth Observation (ITC), and the UNESCO-IHE. The climate modeling part of the study has been carried out at the Royal Meteorological Institute of The Netherlands (KNMI). The comments given by two anynomous reviewers are very much appreciated.

Edited by: L. Pfister

\section{References}

Bastiaanssen, W. G. M. and Ahmad, M. D.: Satellite surveillance of evaporative depletion across the Indus basin, J. Wat. Resour. Res., 38, 1273-1282, 2002.

Benton, G. S., Blackburn, R. T., and Snead, V. W.: The role of the atmosphere in the hydrological cycle, Trans. Am. Geophys. Union, 31, 61-73, 1950.

Bonan, G. B.: Sensitivity of a GCM simulation to inclusion of inland water surfaces, J. Clim., 8, 2691-2704, 1995.

Bosilovich, M. G. and Schubert, S. D.: Water vapor tracers as diagnostics of the regional hydrologic cycle, J. Hydrometeorology, 3 , 149-165, 2002.

Bosilovich, M. G., Sud, Y., Schubert, S. D., and Walker, G. K.: GEWEX CSE sources of precipitation using GCM water vapor tracers, in: Global Energy and Water Cycle Experiment NEWS, 3, 6-7, 2002.

Brubaker, K. L., Entekhabi, D., and Eagleson, P. S.: Estimation of continental precipitation recycling, J. Clim., 6, 1077-1089, 1993.
Brude, G. I. and Zangvil, A.: The Estimation of Regional Precipitation Recycling, Part I: Review of Recycling Models, J. Clim., 14, 2509-2527, 2001.

Budyko, M. I.: Climate and Life, Academic Press, 1974.

Camberlin, P.: Rainfall anomalies in the Source Region of the Nile and their connection with the Indian Summer Monsoon, J. Clim., 10, 1380-1392, 1997.

Conway, D. and Hulme, M.: The impacts of climate variability and climate change in the Nile Basin on future water resources in Egypt, J. Wat. Resour. Dev., 277-296, 1996.

Eagleson, P.S .: The Emergence of Global-Scale Hydrology, J. Wat. Resour. Res., 22, 6-4, 1986.

Eltahir, E. A. B.: A Feedback Mechanism in Annual Rainfall in Central Sudan, J. Hydrol., 110, 323-334, 1989.

Eltahir, E. A. B. and Bras, R. L.: Precipitation Recycling in the Amazon Basin, Quart. J. Roy. Met. Soc., 120, 861-880, 1994.

Farah, H. O.: Estimation of regional evaporation under different weather condition from satellite and meteorological data: a case study in the Naivasha basin, Kenya, Ph.D. thesis, Wageningen University, Wageningen, pp. 170, 2001.

Farmer, G.: Seasonal forecasting of the Kenya coast Short Rains, 1901-1984, J. Climatol., 8, 489-497, 1988.

Giorgi, F. and Mearns, L. O.: Introduction to special section: Regional climate modeling revisited, J. Geophys. Res., 104, 63356352, 1999.

Herman, A., Kumar, V., Arkin, P., and Kousky, J.: Objectively determined 10-day African rainfall estimates created for famine early warning systems, Int. J. Rem. Sens., 18, 2147-2159, 1997.

Howell, P. P., Lock, J. M., and Cobb, S. M. (Eds.): The Jonglei Canal: Impact and opportunity, Cambridge University Press, Cambridge, 537 pp., 1988.

IFS: Integrated Forecast System of ECMWF, http://www.ecmwf int/research/ifsdocs/CY25r1/Physics/Physics-02-2.html

Kite, G. W.: Land surface parameterization of GCM's and macroscale hydrological models, J. Am. Wat. Resour. Assoc., 34, 1247-1254, 1998.

Koster, R., Jouzel, J., Suozzo, R., Russell, G., Broecker, W., Rind, D., and P. Eagleson: Global sources of local precipitation as determined by the NASA/GISS GCM, Geophys. Res. Lett., 13, 121-124, 1986.

Koster, R. D., Dirmeyer, P. A., Hahmann, A. N., Ijpelaar, R., Tyahla, L., Cox, P., and Suarez, M. J.: Comparing the Degree of LandAtmosphere Interaction in Four Atmospheric General Circulation Models, J. Hydrometeorology, 3, 363-375, 2002.

Lafleur, P. M. and Rouse, W. R.: The influence of surface cover and climate on energy partitioning and evaporation in a subarctic wetland, Boundary-Layer Meteorology, 44, 327-347, 1988.

Lenderink, G., van den Hurk, B., van Meigaard, E., van Ulden, A., and Cuijpers, H.: Simulation of present-day climate in RACMO2: first results and model developments, technical report, KNMI, De Bilt, The Netherlands, pp. 24, 2003.

Lipzig van, N.P.M., Meijgaard van, E., and Oerlemans, J.: Evaluation of a regional atmospheric model using measurements of surface heat exchange processes from a site in Antarctica, Mon. Wea. Rep., 127, 1994-2011, 1998.

Masson, V., Champeaux, J.L., Chauvin, F., Mériguet, C., and Lacaze, R.: A global database of land surface parameters at $1 \backslash, \mathrm{km}$ resolution in meteorological and climate models, J. Clim., 16, 1261-1282, http://www.cnrm.meteo.fr/gmme/ 
PROJETS/ECOCLIMAP/page_ecoclimap.htm, 2003.

Mohamed, Y. A., Bastiaanssen, W. G. M., and Savenije, H. H. G.: Spatial variability of evaporation and moisture storage in the swamps of the upper Nile studied by remote sensing techniques, J. Hydrol., 289, 145-164, 2004.

Nicholson, S. E.: A review of climate dynamics and climate variability in eastern Africa, in: The limnology, climatology and paleoclimatology of the East African lakes, edited by: Johnson, T. C. and Odada, E., Gordon and Breach, Amsterdam, 25-56, 1996.

PJTC: First Annual Report of the Permanent Joint Technical Commission for the Nile Waters, Government Printing Press, Khartoum, pp. 138, 1961.

Rudolf, B., Fuchs, T., Schneider, U., and Meyer-Christoffer, A.: Introduction of the Global Precipitation limatology Centre (GPCC), Global Precipitation Climatology Centre, Deutscher Wetterdienst, Offenbach a.M., Germany, 2003.

Savenije, H. H. G.: New definitions for moisture recycling and the relation with land-use changes in the Sahel, J. Hydrol., 167, 5778, 1995.

Schär, Ch., Lüthi, D., Beyerle, U., and Heise, E.: The SoilPrecipitation Feedback: A Process Study with a Regional Climate Model, J. Clim., 12, 722-741, 1999.

Scott, C. A., Bastiaanssen, W. G. M., and Ahmad, M. D.: Mapping root zone soil moisture using remotely sensed optical imagery, ASCE Irrigation and Drainage Engineering, 129, 326-335, 2003.

Shahin, M.: Hydrology of the Nile Basin, Elsevier, Amsterdam, pp. 575,1985

Simmonds, A. J. and Gibson, J. K. (eds.): The ERA40 project plan; ECMWF, Reading, UK, http://www.ecmwf.int/publications/ library/ecpublications/_pdf/era40/ERA40_PRS_1.pdf, 2000.
Smith, M.: CLIMWAT for CROPWAT - A climatic database for irrigation planning and management, FAO Irrigation and Drainage Paper No 49, pp. 113, FAO, Rome, 1993.

Sun, L., Semazzi, F. H. M., Giorgi, F., and Ogallo, L. J.: Application of the NCAR Regional Climate model to Eastern Africa, Part 1: Simulation of the short rains of 1988, J. Geophys. Res., 104, 6529-6548, 1999a.

Sun, L., Semazzi, F. H. M., Giorgi, F., and Ogallo, L. A.: Application of the NCAR Regional Climate model to Eastern Africa, Part II: Simulation of interannual variability of short rains, J. Geophys. Res., 104, 6549-6562, 1999 b.

Sutcliffe, J. V. and Parks, Y. P.: The Hydrology of the Nile, IAHS Special Publication no. 5, IAHS Press, Institute of Hydrology, Wallingford, Oxfordshire OX10 8BB, UK, 1999.

Todd, M. C., Kidd, C., Kniveton, D., and Bellerby, T. J.: A Combined Satellite Infrared and Passive Microwave Technique for Estimation of Small Scale Rainfall, J. of Atmospheric and Oceanic Technology, 18, 742-755, 2001.

Trenberth, K. E.: Atmospheric moisture recycling: Role of advection and local evaporation. J. Clim., 12, 1368-1381, 1999.

van den Hurk, B. J. J. M., Viterbo, P., Beljaars, A. C. M., and Betts, A. K.: Offline validation of the ERA40 surface scheme, ECMWF TechMemo 295, Reading, UK, 2000.

Watson, R. T. and the Core Writing Team (Eds.): Third Assessment Report of the Intergovernmental Panel on Climate Change, Working Group II, Cambridge University Press, UK, pp. 398, 2001. 